\title{
Booklet for Childhood Fever in Out-of-Hours Primary Care: A Cluster-Randomized Controlled Trial
}

Eefje G. P. M. de Bont, MD, MSc'

Geert-Jan Dinant, $M D, P b D^{1}$

Gijs Elshout, $M D, P b D^{2}$

Gijs van Well, $M D, P b D^{3}$

Nick A. Francis, $M D, P b D^{4}$

Bjorn Winkens, $P b D^{5}$

Jochen W. L. Cals, MD, PhD

'Department of Family Medicine, Care and Public Health Research Institute (CAPHRI), Maastricht University, Maastricht, The Netherlands

${ }^{2}$ Department of General Practice, Erasmus MC, University Medical Center Rotterdam, Rotterdam, The Netherlands

${ }^{3}$ Department of Pediatrics, Maastricht University Medical Center (MUMC+), Maastricht, The Netherlands

${ }^{4}$ Division of Population Medicine, School of Medicine, Cardiff University, Cardiff, Wales, United Kingdom

${ }^{5}$ Department of Methodology and Statistics, Research School CAPHRI, Maastricht University, Maastricht, The Netherlands

Conflicts of interest: authors report none.

\section{CORRESPONDING AUTHOR}

Eefje G. P. M. de Bont, MD, MSc Department of Family Medicine Maastricht University

PO Box 616, $6200 \mathrm{MD}$

Maastricht, The Netherlands

eefje.debont@maastrichtuniversity.nl

\begin{abstract}
PURPOSE Fever is the most common reason for a child to be taken to a physician, yet the level of unwarranted antibiotic prescribing remains high. We aimed to determine the effect on antibiotic prescribing of providing an illness-focused interactive booklet on fever in children to out-of-hours primary care clinicians.
\end{abstract}

METHODS We conducted a cluster-randomized controlled trial in 20 out-ofhours general practice centers in the Netherlands. Children aged younger than 12 years with fever were included. Family physicians at the 10 intervention sites had access to an illness-focused interactive booklet between November 2015 and June 2016. The primary outcome was antibiotic prescribing during the index consultation. Analysis was performed by fitting 2-level random intercept logistic regression models.

RESULTS The trial took place among 3,518 family physicians and 25,355 children. The booklet was used in $28.5 \%$ of 11,945 consultations in the intervention group. Compared with usual care, access to the booklet did not significantly alter antibiotic prescribing during the index consultation (odds ratio $=0.90 ; 95 \%$ $\mathrm{Cl}, 0.79-1.02$; prescription rate, $23.5 \%$ vs $25.2 \%$; intracluster correlation coefficient $=0.005)$. In contrast, use of the booklet significantly reduced antibiotic prescribing (odds ratio $=0.83 ; 95 \% \mathrm{Cl}, 0.74-0.94$; prescription rate, $21.9 \%$ vs $25.2 \%$; intracluster correlation coefficient $=0.002$ ). Children managed by family physicians with access to the booklet were less likely to receive any drug prescription, and parents in the booklet group showed a reduced intention to consult again for similar illnesses.

CONCLUSIONS Benefit of an illness-focused interactive booklet in improving outcomes of childhood fever in out-of-hours primary care was largely restricted to the cases in which family physicians actually used the booklet. Insight into reasons for use and nonuse may inform future interventions of this type.

Ann Fam Med 2018;16:314-321. https://doi.org/10.1370/afm.2265.

\section{INTRODUCTION}

$\mathrm{F}$ ever is the most common reason for a child to be taken to a physician, and most fever consultations take place in general practice. ${ }^{1}$ As many parents work during the day and fever typically rises in the early evening, these rates are even higher during out-of-hours care. ${ }^{1,2}$ In most cases, fever is caused by benign viral infections, and general recommendations given by a family physician are sufficient for management. ${ }^{3}$ One in every 3 to 4 children who visit family physician out-of-hours care with a fever receives an antibiotic prescription, however. ${ }^{4,5}$ These prescription rates are nearly twice as high as those during routine office hours. ${ }^{6}$

Consultations are generally driven by parental concerns about harmful consequences of fever. These concerns can be more prominent when needing to consult a family physician on call who is not their personal family physician. ${ }^{7}$

Previous studies have shown that antibiotic prescribing is strongly influenced by patients' expectations and that family physicians experience pressure from patients to prescribe antibiotics. ${ }^{8}$ Most parents of 
a febrile child in fact do not expect antibiotics, but seek reassurance and consistent, reliable information about fever, specific symptoms, and self-management strategies. ${ }^{7,9,10}$ Nevertheless, conveying evidence-based information to parents is challenging for family physicians, even more so in time-pressured consultations in the evening and at night. ${ }^{11}$ A systematic review showed that information leaflets offered during family physician consultations for common infections are promising tools to provide parents with a safety net and to reduce antibiotic prescribing. ${ }^{12}$ No studies of leaflets have been performed during out-of-hours care or in childhood fever consultations, however.

The CHILdhood Infections (CHILI) study therefore aimed to develop and assess the effectiveness of an illness-focused interactive fever booklet for parents on the management of children presenting with fever at family physician out-of-hours care.

\section{METHODS}

\section{Study Design and Participants}

We performed a cluster-randomized controlled trial with randomization at the level of family physician outof-hours centers. Recruited centers were randomized to 2 arms: an illness-focused interactive booklet arm or a care-as-usual arm. Family physicians working at intervention centers were given access to the booklet and were free to use it or not during childhood fever consultations at their own discretion. A fully detailed description of the development of the intervention and the methods used has been previously published. ${ }^{13}$

Twenty family physician out-of-hours centers across the Netherlands providing care for 3,557,206 residents participated in this trial from November 2015 to June 2016. Family physician out-of-hours care is defined as primary care provided beyond office hours every day between 5:00 PM to 8:00 AM and the entire weekend. ${ }^{14}$ Since 2000 , this care has been provided by approximately 120 to 130 large-scale family physician centers. In each center, 50 to 200 family physicians rotate shifts, providing out-of-hours care to residents of a single specific region in which their daytime practice is located. ${ }^{14}$ Hence, in most out-of-hours consultations, patients will not see their own family physician. These centers are essentially intended for urgent help requests that cannot wait until the next day. Furthermore, Dutch family physicians are gatekeepers for secondary care; therefore, they refer to pediatricians only those children they deem to have a medical indication for pediatrician care.

Patients were eligible for inclusion if they were aged 3 months to 12 years and the family physician recorded the consultation as a fever-related consultation. This study was approved by the ethical commit- tee of Zuyderland-Zuyd (METC Z) in Heerlen, the Netherlands (Ref 14-N-171).

\section{Procedures and Outcomes}

The content of the illness-focused interactive booklet was developed in a multistage process using a nationwide survey among parents, focus group sessions, and semistructured interviews with parents, family physicians, and triage nurses working or consulting during out-of-hours family physician care, along with an extensive literature research and expert discussions.,15 The booklet had the following components:

- A traffic light system for childhood fever in general, with advice on when to consult a family physician (red symptoms) and information on self-management strategies, as well as specific traffic lights for infections of the upper respiratory tract (cough, cold, and sore throat), acute otitis media (earache), and gastrointestinal symptoms (abdominal pain, vomiting, and diarrhea),

- Information on the benefits and harms of antibiotic treatment,

- An overview of the natural duration of common infections in children,

- A table with weight-banded paracetamol dosage schemes, and

- Advice and information on febrile convulsions and skin rash.

The booklet was designed to be used in the final part of a clinical consultation, to facilitate an interactive discussion between parents and family physicians. Specifically, we expected that family physicians would have the opportunity to highlight and mark specific signs, symptoms, and questions that were relevant for a given child, and provide parents with tailored advice and a safety net for the child's clinical problem. This approach not only ensured that the advice family physicians gave was tailored to parents' specific questions, but also facilitated communication and resolution of misconceptions between parents and family physicians regarding expectations of the consultation.

The primary outcome was an antibiotic prescription during the index consultation. The secondary outcomes, assessed in the complete sample, were repeated consultations during out-of-hours care; antibiotic prescriptions during repeated consultations at the family physician out-of-hours center; overall medication prescriptions during the index consultation and subsequent 2 weeks of follow-up; and referral to secondary care. Data were collected in a coded, automatic manner from the center databases, and were supplied by an independent party that is responsible for the electronic patient files software (Labelsoft Clinical IT BV, CompuGroup Medical AG). Every time the family physician closed the patient 
file of a child younger than 12 years, the software displayed a pop-up message: "Did this child have a fever (at home or during the consultation)?" This message occurred after the parents had left the consultation room. We included in the study children for whom the family physician selected "yes." Family physicians working at intervention sites received an additional question: "Did you hand out the booklet?" The International Classification of Primary Care (ICPC) coding system was used to map reasons for the consultation.

Data on additional secondary outcomes were collected among a subsample of parents using telephone surveys during 3 two-week periods in months 2, 4, and 6 . A triage nurse provided parents with information about the study during their visit in these weeks. If parents in this subsample gave written informed consent, they were asked to participate in a telephone survey 2 weeks after the index consultation. The surveys were used to question parents about intention to reconsult for the same fever episode and in the future, receipt and use of antibiotics at reconsultation, parental satisfaction (using a visual analog scale [VAS] rating), parental reassurance (reassured vs not reassured, and VAS rating), self-reported complications, consultations with their own family physician, and their opinion about the booklet (VAS ratings for intention to use again, most important section).

\section{Randomization and Masking}

We chose cluster randomization to reduce the risk of contamination. We stratified participating family physician out-of-hours centers by size (10 smaller vs 10 larger centers, with a cut-off point of fewer or more than 20,500 consultations per year), to ensure equal distribution of size between the intervention and control groups. A blinded, independent researcher (B.W.) performed a computer-based randomization with random permuted blocks of 2. Centers were informed of their allocation only after agreeing to participate.

\section{Statistical Analysis}

The primary outcome was the antibiotic prescribing rate during the index consultation (dichotomous). The required numbers of centers (clusters) and participants were based on the following assumptions: (1) an intracluster correlation coefficient (ICC) of $0.01{ }^{16}{ }^{16}$ (2) an alpha of .05 and power of $0.80,(3)$ antibiotics prescribed to $25 \%$ of control group and $19 \%$ of intervention group, and (4) a $10 \%$ loss to follow-up and $10 \%$ efficiency loss based on unequal cluster sizes. ${ }^{17}$ These parameters resulted in a need for 20 centers to acquire the same power as an individual randomized controlled trial (with an effective sample size of 737 patients in both groups [1,474 in total] for an individual-randomized controlled trial based on the $\chi^{2}$ test). Taking the cluster effect into account, the total recruitment target for this cluster-randomized trial was 20,000 children, recruited at 20 family physician out-of-hours centers (10 control, 10 intervention).

To ascertain the required sample size, we performed a retrospective cohort study. ${ }^{4}$ We identified an average of 15 consultations per day for children with fever and fever-related conditions. On the basis of this cohort study and a pilot study, we assumed that 1,000 children per center could be included in the trial in 6 months.

Initial descriptive statistics and frequencies were generated to summarize the data using SPSS Statistics for Windows version 21.0 (IBM Corp). Statistical analyses were then performed based on the intention-to-treat principle by fitting 2-level (center and patient) random intercept logistic regression models using MLwiN software version 2.22 (Centre for Multilevel Modelling, University of Bristol). The fixed parameters were center group (intervention vs control) and size (small vs large). We accounted for clustering in the data by using a random intercept at the center level. We also checked whether the results changed after including patient sex, age, and socioeconomic status in this model.

We expected compliance (use of the booklet) to be lower than $100 \%$ because of the nature and pragmatic design of the trial. Unfortunately, there were no previous comparable trials or studies that provided us with an indication of how high the level of compliance would be. We therefore chose to perform prespecified additional secondary analyses adjusting for compliance (control vs actual use of booklet instead of control vs access to booklet) using complier average causal effect (CACE) analysis..$^{13}$ Randomization ensured that, on average, the proportion of compliers in the control group would have been the same as that in the group with booklet access. ${ }^{18}$ We therefore estimated the proportion of unobserved (would-be) compliers in the control group from the proportion observed in the intervention group. This analysis was based on the assumption that there could be only compliers and never-takers (nonusers of the intervention), as family physicians in the control arm had no access to the booklet. We also assumed that there would be no effect of randomization on the outcome (exclusion restriction). We then calculated the odds ratio (OR) adjusted for compliers and corrected for stratification during randomization based on center size (small vs large)..$^{18,19}$ During outcome data analysis, researchers were blinded to the group assignment.

\section{RESULTS}

A total of 106,014 telephone contacts for children took place at the 20 participating out-of-hours centers 
Figure 1. Trial participant recruitment and inclusion.

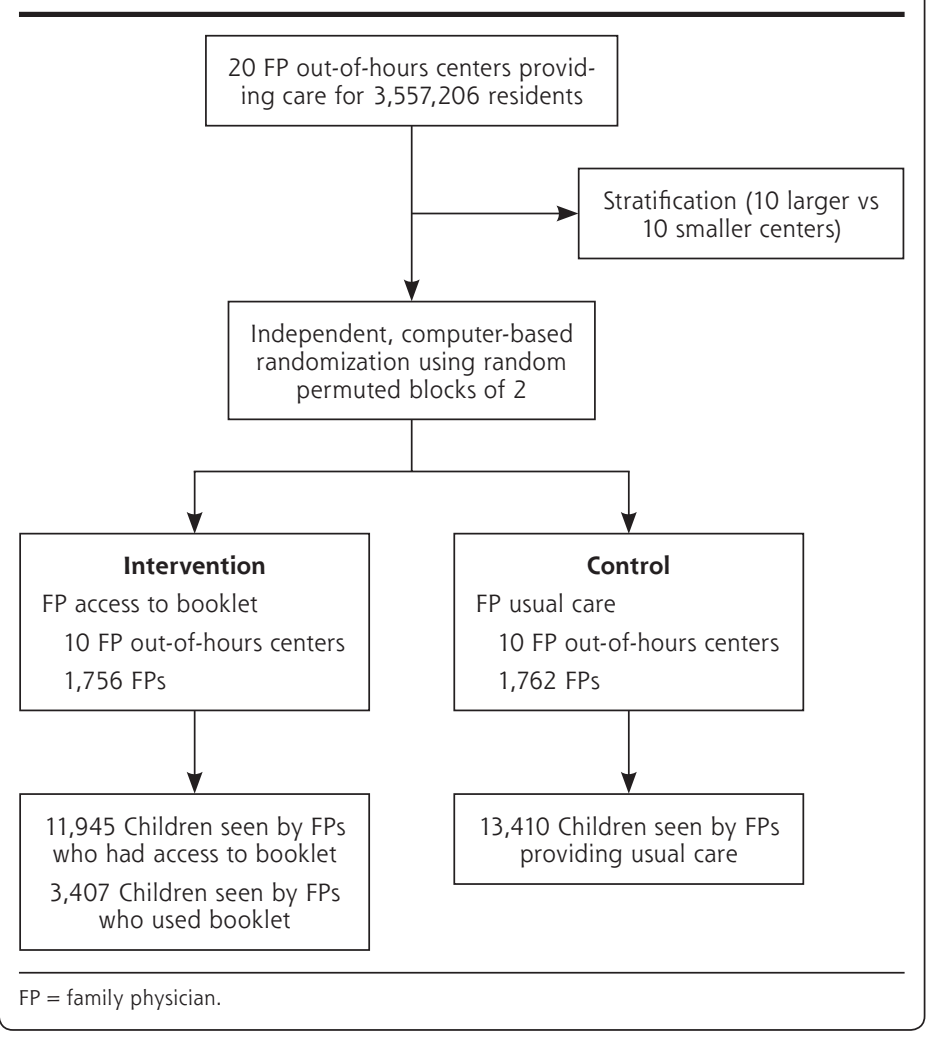

the out-of-hours centers within 2 weeks of the index consultation for the same illness episode, or in out-of-hours repeated consultation rates within 6 months after randomization or referral rates to secondary care at the index consultation.

Children in the group with booklet access were less likely than usual care counterparts to receive a prescription for any medication including nonantibiotic medications $(\mathrm{OR}=0.87 ; 95 \% \mathrm{CI}, 0.77$ 0.97 i ICC $=0.004)$. The most commonly prescribed nonantibiotic medications were xylomethazoline, salbutamol, and ibuprofen (Supplemental Table 1, available at http:// www.annfammed.org/content/16/4/314/ suppl/DC1/). Adjusting for sex, age, and socioeconomic status had no effect on any of these outcomes. Mean antibiotic prescription rates varied between the 3 most common ICPC codes, as shown in Table 3. Amoxicillin was the most commonly prescribed antibiotic, accounting for $76.1 \%$ of all antibiotic prescriptions in the trial.

When analyses took compliance with the intervention into consideration, there was a significant reduction in antibiotic prescribing among the 3,407 children seen by family during the trial period (Figure 1). Of these contacts, $36.1 \%$ were fever related, and $77.3 \%$ of these feverrelated contacts resulted in a face-to-face consultation with a family physician. A total of 3,518 family physicians (range per center, 73 to 273) recruited to the trial 25,355 children (11,945 in the intervention group and 13,410 in the control group, with number varying from 366 to 2,756 per center, equally divided across groups).

Baseline characteristics of the enrolled children are shown in Table 1. The distribution of age, sex, socioeconomic status, and ICPC diagnosis were similar between the intervention and control groups and between centers.

In the intervention group, the booklet was used in only 3,407 (28.5\%) of the encounters (range across centers, $23.1 \%$ to $38.5 \%)$. Antibiotic prescribing did not differ significantly between centers in which family physicians had access to the booklet and control centers $(\mathrm{OR}=0.90 ; 95 \%$ CI, 0.79-1.02; ICC =0.005) (Table 2). There were no significant differences in rates of repeated consultations at
Table 1. Patient Characteristics by Group and Overall

\begin{tabular}{|c|c|c|c|}
\hline Characteristic & $\begin{array}{c}\text { Usual Care } \\
\text { Group } \\
(n=13,410)\end{array}$ & $\begin{array}{c}\text { Access to } \\
\text { Booklet Group } \\
(n=11,945)\end{array}$ & $\begin{array}{c}\text { Total } \\
(\mathrm{N}=25,355)\end{array}$ \\
\hline Age, mean (SD), y & $3.2(2.7)$ & $3.3(2.7)$ & $3.2(2.7)$ \\
\hline Male, No. (\%) & $7,100(52.9)$ & $6,313(52.9)$ & $13,413(52.9)$ \\
\hline \multicolumn{4}{|l|}{$\begin{array}{l}\text { Parent socioeconomic } \\
\text { status, No. (\%) }\end{array}$} \\
\hline Low & $2,261(16.9)$ & $1,826(15.4)$ & $4,087(16.2)$ \\
\hline Middle & $9,055(67.8)$ & $8,459(71.5)$ & $17,514(69.5)$ \\
\hline High & $2,032(15.2)$ & $1,550(13.1)$ & $3,582(14.2)$ \\
\hline \multicolumn{4}{|l|}{ Top ICPC codes, No. (\%) } \\
\hline A03.00: fever & $2,471(18.5)$ & $2,174(18.2)$ & $4,645(18.4)$ \\
\hline $\begin{array}{l}\text { R74.00: acute upper respi- } \\
\text { ratory tract infection }\end{array}$ & $2,653(19.8)$ & $2,357(19.9)$ & $5,010(19.8)$ \\
\hline $\begin{array}{l}\text { H71.00: acute otitis } \\
\text { media/myringitis }\end{array}$ & $1,872(14.0)$ & $1,604(13.5)$ & $3,476(13.8)$ \\
\hline
\end{tabular}


Table 2. Primary and Secondary Outcomes in the Total Trial Population

\begin{tabular}{|c|c|c|c|c|c|c|}
\hline Outcome & $\begin{array}{c}\text { Usual Care } \\
\text { Group, No. (\%) } \\
(n=13,410)\end{array}$ & $\begin{array}{c}\text { Access to } \\
\text { Booklet Group, } \\
\text { No. }(\%) \\
(n=11,945)\end{array}$ & $\begin{array}{l}\text { Access to } \\
\text { Booklet, OR } \\
(95 \% \mathrm{Cl})\end{array}$ & $\begin{array}{c}\text { Use of } \\
\text { Booklet, } \\
\text { No. (\%) } \\
(n=3,407)\end{array}$ & $\begin{array}{c}\text { Use of } \\
\text { Booklet, } \\
\text { Unadjusted } \\
\text { OR }(95 \% \mathrm{CI})^{\mathrm{a}}\end{array}$ & $\begin{array}{l}\text { Use of } \\
\text { Booklet, } \\
\text { Adjusted OR } \\
(95 \% \mathrm{Cl})^{\mathrm{b}}\end{array}$ \\
\hline \multicolumn{7}{|l|}{ Primary outcome } \\
\hline $\begin{array}{l}\text { Antibiotic prescrip- } \\
\text { tion during index } \\
\text { consultation }\end{array}$ & $3,375(25.2)$ & $2,809(23.5)$ & $\begin{array}{c}0.90 \\
(0.79-1.02)\end{array}$ & $746(21.9)$ & $\begin{array}{c}0.83 \\
(0.74-0.94)^{c}\end{array}$ & $\begin{array}{c}0.85 \\
(0.75-0.97)^{c, d}\end{array}$ \\
\hline \multicolumn{7}{|l|}{ Secondary outcomes } \\
\hline $\begin{array}{l}\text { Reconsultation of } \mathrm{OOH} \\
\text { within } 2 \text { wk }\end{array}$ & $861(5.5)$ & $741(5.4)$ & $\begin{array}{c}0.95 \\
(0.83-1.09)\end{array}$ & $165(4.3)$ & $\begin{array}{c}0.97 \\
(0.80-1.16)\end{array}$ & $\begin{array}{c}0.95 \\
(0.79-1.15)\end{array}$ \\
\hline $\begin{array}{l}\text { Antibiotic prescription } \\
\text { OOH from index } \\
\text { consultation through } \\
\text { 2-wk follow-up }\end{array}$ & $3,570(26.6)$ & $2,975(24.9)$ & $\begin{array}{c}0.90 \\
(0.79-1.02)\end{array}$ & $797(23.4)$ & $\begin{array}{c}0.84 \\
(0.75-0.95)^{c}\end{array}$ & $\begin{array}{c}0.86 \\
(0.76-0.96)^{c, d}\end{array}$ \\
\hline $\begin{array}{l}\text { Reconsultation of } \mathrm{OOH} \\
\text { during } 6 \text {-mo study } \\
\text { period }\end{array}$ & $1,262(8.1)$ & $1,145(8.3)$ & $\begin{array}{c}0.99 \\
(0.84-1.18)\end{array}$ & $283(7.3)$ & $\begin{array}{c}0.97 \\
(0.74-1.29)\end{array}$ & $\begin{array}{c}0.94 \\
(0.71-1.25)\end{array}$ \\
\hline $\begin{array}{l}\text { Referral to secondary } \\
\text { care at index } \\
\text { consultatione }\end{array}$ & $1,066(7.9)$ & $893(7.5)$ & $\begin{array}{c}1.03 \\
(0.87-1.21)\end{array}$ & $\mathrm{n} / \mathrm{a}$ & $\mathrm{n} / \mathrm{a}$ & $\mathrm{n} / \mathrm{a}$ \\
\hline $\begin{array}{l}\text { Prescription of any } \\
\text { kind }\end{array}$ & $5,162(38.5)$ & $4,245(35.5)$ & $\begin{array}{c}0.87 \\
(0.77-0.97)^{c}\end{array}$ & $1,114(32.7)$ & $\begin{array}{c}0.77 \\
(0.70-0.86)^{c}\end{array}$ & $\begin{array}{c}0.79 \\
(0.71-0.87)^{\mathrm{c,d}}\end{array}$ \\
\hline \multicolumn{7}{|c|}{$\mathrm{n} / \mathrm{a}=$ not applicable because parents of children who were referred did not receive the booklet; $\mathrm{OOH}=$ out-of-hours care; $\mathrm{OR}=$ odds ratio. } \\
\hline \multicolumn{3}{|c|}{$\begin{array}{l}\text { d Significant difference compared with control group }(P<.05) \text {. In complier-adjusted causal effect }(C A C E) \text { analysis, OR }(95 \% \text { CI) was } 0.71(0.63-0.79) \text { for antibiotic prescrip- } \\
\text { tion during index consultation; } 0.83(0.75-0.93) \text { for antibiotic prescription during index consultation and } 2 \text {-wk follow-up; } 0.62(0.57-0.69) \text { for prescription of any kind. } \\
\text { e Total of } 187(5.5 \%) \text { of the children in booklet group were referred. }\end{array}$} & $\begin{array}{l}\text { causal effect (CACE) } \\
\text { dex consultation and }\end{array}$ & $\begin{array}{l}\text { nalysis, OR }(95 \% \text { C } \\
\text {-wk follow-up; } 0.6\end{array}$ & $\begin{array}{l}\text { was } 0.71(0.63-0.79) \\
(0.57-0.69) \text { for prescr }\end{array}$ & $\begin{array}{l}\text { or antibiotic prescrip- } \\
\text { otion of any kind. }\end{array}$ \\
\hline
\end{tabular}

ICC $=0.002$ ). After correcting for compliance, we also found no significant differences in out-of-hours reconsultation rates within 6 months after randomization, or in referral rates to secondary care at the index consultation. But children for whom the booklet was actually used were less likely to receive a prescription for any medication including a nonantibiotic medication $(\mathrm{OR}=0.77 ; 95 \% \mathrm{CI}, 0.70-0.86$; $\mathrm{ICC}=0.001)$.

In the CACE analysis, booklet use was associated with reduced odds of antibiotic prescriptions during index consultations $(\mathrm{OR}=0.71 ; 95 \% \mathrm{CI}, 0.63-0.79)$ and of any prescription during index consultations $(\mathrm{OR}=0.62 ; 95 \% \mathrm{CI}, 0.57-0.69)$. The ICC for compliance was 0.09 .

Supplemental Table 2 (available at http://www. annfammed.org/content/16/4/314/suppl/DC1/) shows patient characteristics for the subgroups having access to booklet vs using the booklet vs not using the booklet in the intervention group; Supplemental Table 3 (available at http:// www.annfammed.org/
content/16/4/314/supp1/DC1/) shows the same data for parents participating in the telephone survey. Parents in the subsample interviewed by telephone were comparable to those in the main study (Supplemental Table 3, available at http://www.annfammed.org/ content/16/4/314/suppl/DC1/). Of the 553 parents surveyed, $36.0 \%$ indicated they received the booklet. In the control group, $2.8 \%$ of parents reported receiving written patient information or referral to a website with patient information. A minority, $23.5 \%$ of the 553 parents, reported having visited their own family physician before consulting out-of-hours care, with no significant difference between intervention and control groups. We observed a significant reduction in intention to reconsult
Table 3. Antibiotic Prescribing Rates by Top ICPC Codes

\begin{tabular}{|c|c|c|c|}
\hline ICPC Code & $\begin{array}{l}\text { Usual Care } \\
\text { No.In (\% Within } \\
\text { ICPC Code) }\end{array}$ & $\begin{array}{l}\text { Access to Booklet } \\
\text { No.In ( } \% \text { Within } \\
\text { ICPC Code) }\end{array}$ & $\begin{array}{l}\text { Use of Booklet } \\
\text { No.In ( } \% \text { Within } \\
\text { ICPC Code) }\end{array}$ \\
\hline A03.00 fever & $191 / 2,471$ (7.7) & $144 / 2,174(6.6)$ & $51 / 835(6.1)$ \\
\hline $\begin{array}{l}\text { R74.00 acute upper respira- } \\
\text { tory tract infection }\end{array}$ & $486 / 2,653(18.3)$ & $359 / 2,357(15.2)$ & $102 / 789$ (12.9) \\
\hline $\begin{array}{l}\text { H71.00 acute otitis media/ } \\
\text { myringitis }\end{array}$ & $1,246 / 1,872(66.6)$ & $1,034 / 1,604(64.5)$ & $289 / 449(64.4)$ \\
\hline
\end{tabular}




\section{Table 4. Parent-Reported Secondary Outcomes Based on Telephone Survey}

\begin{tabular}{|c|c|c|c|}
\hline Secondary Outcome & $\begin{array}{l}\text { Usual Care } \\
(n=250)\end{array}$ & $\begin{array}{c}\text { Access to } \\
\text { Booklet } \\
(n=303)\end{array}$ & $\begin{array}{c}\text { Use of } \\
\text { Booklet } \\
(n=109)\end{array}$ \\
\hline Reconsultation with own FP within 2 wk, No. (\%) & $73(29.2)$ & $104(34.3)$ & $37(33.9)$ \\
\hline $\begin{array}{l}\text { Antibiotic prescription by own FP during recon- } \\
\text { sultations within } 2 \text { wk, No./n (\%) }\end{array}$ & $26 / 73(35.6)$ & $27 / 104(26.0)$ & $12 / 37(32.4)$ \\
\hline Hospital admission within 2 wk, No. (\%) & $17(6.8)$ & $21(6.9)$ & $6(5.5)$ \\
\hline \multicolumn{4}{|l|}{ Satisfaction with care } \\
\hline Satisfaction VAS score, ${ }^{a}$ median (IQR) & $8.0(7.0-8.0)$ & $8.0(7.0-9.0)$ & $8.0(7.0-9.0)$ \\
\hline Reassurance VAS score, ${ }^{a}$ median (IQR) & $8.0(7.0-8.0)$ & $8.0(7.0-8.0)$ & $8.0(8.0-9.0)$ \\
\hline VAS score for booklet, ${ }^{a}$ median (IQR) & - & - & $8.0(8.0-9.0)$ \\
\hline Intention to reconsult for similar illness, No. (\%) & $211(84.4)$ & $229(75.6)^{b}$ & $78(71.6)^{b}$ \\
\hline \multicolumn{4}{|c|}{$\mathrm{FP}=$ family physician; $\mathrm{IQR}=$ interquartile range; $\mathrm{VAS}=$ visual analog scale. } \\
\hline \multicolumn{4}{|c|}{$\begin{array}{l}\text { a Scores ranged from } 1 \text { (most negative answer) to } 10 \text { (most positive answer). } \\
\text { b Significant difference compared with control group }(P<.05) \text {. }\end{array}$} \\
\hline
\end{tabular}

actual practice and to the considerations of family physicians' prescribing decisions in childhood fever consultations. As in everyday practice, we anticipated that not every child in the intervention group would receive a booklet. Moreover, family physicians were provided with only brief e-mail instructions about use of the intervention. We specifically decided not to provide a special, more intensive training or meeting as doing so for similar illnesses among parents in the group in which family physicians had access to booklet $(\mathrm{OR}=0.55 ; 95 \%$ CI $0.35-0.85 ; 75.6 \%$ vs $84.4 \%$, ICC <.001) (Table 4 ).

\section{DISCUSSION}

Family physicians having easy access to an illnessfocused interactive booklet on childhood fever and common infections used the booklet in fewer than 1 in 3 fever-related consultations in out-of-hours general practice. Access to the booklet did not significantly reduce antibiotic prescriptions at index consultations; however, our prespecified analysis suggested that actual use of the booklet reduced antibiotic prescriptions at the index consultation, overall medication prescriptions, and parents' intention to reconsult for future similar illnesses.

This is one of the largest cluster-randomized controlled trials ever performed in general practice and the first to assess the effectiveness of a booklet for one of the most common reasons for childhood consultations and antibiotic prescriptions. We chose a cluster-randomized design because individual randomization would have led to a high risk of contamination. Specific considerations for choosing this design are described elsewhere. ${ }^{13}$

Family physicians believe that interventions for use during out-of-hours care need to be readily available in every consultation room. ${ }^{15}$ Widespread availability acts as a reminder to use them. This was also the reason we chose a paper booklet in an era of Internet and smartphone applications. The cluster design enabled us to provide every consultation room at intervention centers with the necessary material, making the study more pragmatic. A cluster-randomized controlled trial, however, has important limitations.

With our trial's cluster-randomization and pragmatic nature, we aimed to get as close as possible to would have made the intervention more costly and unlikely to be undertaken in actual daily practice. A recent Cochrane review on this subject backed up our approach. ${ }^{20}$ We chose to perform a pragmatic study, allowing for variation and facilitating possible implementation into daily practice.

We expected compliance (use of the booklet) to be lower than $100 \%$, but had no comparable data informing us what actual compliance would likely be, so we had to consider and prespecify additional analyses correcting for compliance during the design of this study. ${ }^{13}$ The chosen complier analysis, CACE, enabled us to evaluate the effect of actually receiving the booklet on antibiotic prescriptions in a more robust way than simply undertaking a per-protocol analysis alongside the intention-to-treat analysis. Estimation of CACE is, however, dependent on potentially challengeable assumptions that cannot be tested, which means that a risk of postrandomization recruitment bias cannot be completely excluded. ${ }^{18,21}$ As is shown in Supplemental Table 2, however, characteristics of those children for whom the booklet was used were comparable to those for whom the booklet was not used. The only noticeable differences were in the percentage of children with ICPC code A03.00 for fever and R74.00 for acute upper respiratory tract infection between groups using and not using the booklet. These differences could suggest that family physicians were more likely to use the booklet in cases of fever without a specific diagnosis. Furthermore, best available statistical models and software do not allow for correction of the cluster effect in a CACE analysis with a dichotomous outcome. Nevertheless, an increasing number of studies have shown that a CACE analysis is much closer to the real-world intention-totreat estimates of treatment effects. ${ }^{8,21,22}$ 
Our trial shows that handing out patient information leaflets about childhood fever during routine out-of-hours care is very uncommon, as only $2.8 \%$ of parents consulting at control centers reported receiving such information. This result indicates that even in the bread-and-butter condition of childhood fever, uptake and handout of available patient information materials (either written or online) is very low in routine care, even though they are crucial for parents to learn about self-management strategies and alarm symptoms. Provision of patient information materials is largely a clinician behavior, however, and could be influenced by relatively light-touch interventions such as desk or computer prompts, or even dissemination of the results of this and similar studies.

Blinding of the participating family physicians regarding the intervention was not possible, but to minimize the risk of bias we blinded them to the outcome in both groups and blinded outcome assessors. In terms of generalizability, more than 1 in 3 active family physicians in the Netherlands took part in the study, and we believe that this population is representative of the wider family physician population in the country. In addition, the Netherlands has one of the lowest antibiotic prescribing rates in the world. One could expect the effect of the booklet to be larger in countries with higher antibiotic prescribing rates.

We found a significantly lower antibiotic prescription rate of $25.2 \%$ in the usual care group vs $21.9 \%$ in the group in which the booklet was actually used. The difference was less than the absolute $6 \%$ difference ( $25 \%$ vs $19 \%$ ) that we chose for our sample size calculation. Our findings are in keeping with a previous UK study that found a significant reduction in antibiotic prescribing with use of an interactive booklet about childhood respiratory tract infections during in-hours general practice. ${ }^{23}$ That study reported a larger reduction in antibiotic prescribing than we observed, but only among those who agreed to participate. Our study included all fever-related consultations and therefore provides results that are more likely to be indicative of real-world effects. Other studies examining the impact of information leaflets on antibiotic prescriptions in primary care have mainly been undertaken among adults and have focused on specific symptoms, such as acute cough. ${ }^{12}$

Ideally, such behavioral interventions should be combined with other interventions aimed at reducing unwarranted antibiotic prescriptions, such as improved diagnostics, point-of-care tests, interactive workshops, ${ }^{24}$ and peer comparison. ${ }^{25}$

In conclusion, the low-cost and light-touch intervention evaluated in our CHILI trial focused on the illness experience of parents and would be easy to implement into routine care. We found insufficient evidence to conclude that simply providing access to a booklet on childhood fever during out-of-hours care results in reduced antibiotic prescriptions; however, when correcting for actual use of the booklet, which was low, we found a reduction in antibiotic prescriptions. The reduction in antibiotic prescribing found in this implementation study of all children seen at out-of-hours care with fever seems modest. It provides evidence, however, of the likely real-world benefits of this intervention, and evidence of the intervention's efficacy when used could probably increase its use. The study is therefore highly relevant to the aim of reducing antimicrobial resistance.

To read or post commentaries in response to this article, see it online at http://www.AnnFamMed.org/content/16/4/314.

Key words: children; antibiotics; fever; infections; family practice; out-of-hours; inappropriate prescribing; practice patterns, physicians'; primary care; pediatrics

Submitted November 3, 2017; submitted, revised, March 27, 2018; accepted April 30, 2018.

Author contributions: J.C. and E.B conceived the idea for this study. E.B. is the principal investigator and wrote the first version of the manuscript. J.C., G.E., G.W., N.F., B.W., and G.D. were involved in the development of the protocol, and all authors commented on the first draft and all further revisions of this manuscript.

Funding support: The Netherlands Organization for Health Research and Development (ZonMW grant 836-021022) funded this study. J.C. is supported by a Veni-grant (91614078) of the Netherlands Organisation for Health Research and Development (ZonMw).

Disclaimer: The funders of the study had no role in study design, data collection, data analysis, data interpretation, or writing of the manuscript.

Trial registration: This trial was registered at ClinicalTrials.gov, NCT02594553.

Acknowledgments: We would like to thank Mascha Twellaar and Paddy Hinssen for their data support in this study. We would also like to acknowledge all the participating FPs, parents, and out-of-hours centers in this study.

Consort statement: This study is reported in accordance with the Consolidated Standards of Reporting Trials (CONSORT) and extension statement for cluster-randomized controlled trials.

Supplementary Materials: Available at http://www.AnnFamMed. org/content/16/4/314/suppl/DC1/.

\section{References}

1. National Institute of Clinical Excellence. NICE Guideline: Feverish Illness in Children. London, UK: National Institute of Clinical Excellence; 2013.

2. de Bont EG, Francis NA, Dinant GJ, Cals JW. Parents' knowledge, attitudes, and practice in childhood fever: an internet-based survey. Br J Gen Pract. 2014;64(618):e10-e16. 
3. Cioffredi LA, Jhaveri R. Evaluation and management of febrile children: a review. JAMA Pediatr. 2016;170(8):794-800.

4. de Bont EG, Lepot JM, Hendrix DA, et al. Workload and management of childhood fever at general practice out-of-hours care: an observational cohort study. BMJ Open. 2015;5(5):e007365.

5. Elshout G, Kool M, Van der Wouden JC, Moll HA, Koes BW, Berger MY. Antibiotic prescription in febrile children: a cohort study during out-of-hours primary care. J Am Board Fam Med. 2012;25(6): 810-818.

6. Otters HB, van der Wouden JC, Schellevis FG, van Suijlekom-Smit LW, Koes BW. Trends in prescribing antibiotics for children in Dutch general practice. J Antimicrob Chemother. 2004;53(2):361-366.

7. de Bont EG, Loonen N, Hendrix DA, Lepot JM, Dinant GJ, Cals JW. Childhood fever: a qualitative study on parents' expectations and experiences during general practice out-of-hours care consultations. BMC Fam Pract. 2015;16:131.

8. Macfarlane J, Holmes W, Macfarlane R, Britten N. Influence of patients' expectations on antibiotic management of acute lower respiratory tract illness in general practice: questionnaire study. BMJ. 1997;315(7117):1211-1214.

9. Cabral C, Ingram J, Lucas PJ, et al. Influence of clinical communication on parents' antibiotic expectations for children with respiratory tract infections. Ann Fam Med. 2016;14(2):141-147.

10. Mangione-Smith R, Zhou C, Robinson JD, Taylor JA, Elliott MN, Heritage J. Communication practices and antibiotic use for acute respiratory tract infections in children. Ann Fam Med. 2015;13(3):221-227.

11. Butler CC, Rollnick S, Pill R, Maggs-Rapport F, Stott N. Understanding the culture of prescribing: qualitative study of general practitioners' and patients' perceptions of antibiotics for sore throats. BMJ. 1998;317(7159):637-642.

12. de Bont EG, Alink M, Falkenberg FC, Dinant GJ, Cals JW. Patient information leaflets to reduce antibiotic use and reconsultation rates in general practice: a systematic review. BMJ Open. 2015;5(6): e007612.

13. de Bont EG, Dinant GJ, Elshout G, et al. An illness-focused interactive booklet to optimise management and medication for childhood fever and infections in out-of-hours primary care: study protocol for a cluster randomised trial. Trials. 2016;17(1):547.

14. Giesen PSM, Huibers L, Grol R, Wensing M. Quality of after-hours primary care in the Netherlands: a narrative review. Ann Intern Med. 2011;155(2):108-113.
15. de Bont EG, Peetoom KK, Moser A, Francis NA, Dinant GJ, Cals JW. Childhood fever: a qualitative study on GPs' experiences during out-of-hours care. Fam Pract. 2015;32(4):449-455.

16. Adams G, Gulliford MC, Ukoumunne OC, Eldridge S, Chinn S, Campbell MJ. Patterns of intra-cluster correlation from primary care research to inform study design and analysis. J Clin Epidemiol. 2004; 57(8):785-794.

17. van Breukelen GJ, Candel MJ, Berger MP. Relative efficiency of unequal versus equal cluster sizes in cluster randomized and multicentre trials. Stat Med. 2007;26(13):2589-2603.

18. Dunn G, Maracy M, Dowrick C, et al; ODIN group. Estimating psychological treatment effects from a randomised controlled trial with both non-compliance and loss to follow-up. Br J Psychiatry. 2003; 183:323-331.

19. White IR. Uses and limitations of randomization-based efficacy estimators. Stat Methods Med Res. 2005;14(4):327-347.

20. O'Sullivan JW, Harvey RT, Glasziou PP, McCullough A. Written information for patients (or parents of child patients) to reduce the use of antibiotics for acute upper respiratory tract infections in primary care. Cochrane Database Syst Rev. 2016;11:CD011360.

21. Jo B. Model misspecification sensitivity analysis in estimating causal effects of interventions with non-compliance. Stat Med. 2002;21(21): 3161-3181.

22. Gillespie D, Hood K, Farewell D, et al; GRACE consortium. Adherence-adjusted estimates of benefits and harms from treatment with amoxicillin for LRTI: secondary analysis of a 12-country randomised placebo-controlled trial using randomisation-based efficacy estimators. BMJ Open. 2015;5(3):e006160.

23. Francis N, Butler C, Hood K, Simpson S, Wood F, Nuttall J. Effect of using an interactive booklet about childhood respiratory tract infections in primary care consultations on reconsulting and antibiotic prescribing: a cluster randomised controlled trial. BMJ. 2009;339: b2885.

24. Little P, Stuart B, Francis N, et al.; GRACE consortium. Effects of Internet-based training on antibiotic prescribing rates for acute respiratory-tract infections: a multinational, cluster, randomised, factorial, controlled trial. Lancet. 2013;382(9899):1175-1182.

25. Meeker D, Linder JA, Fox CR, et al. Effect of behavioral interventions on inappropriate antibiotic prescribing among primary care practices: a randomized clinical trial. JAMA. 2016;315(6):562-570. 